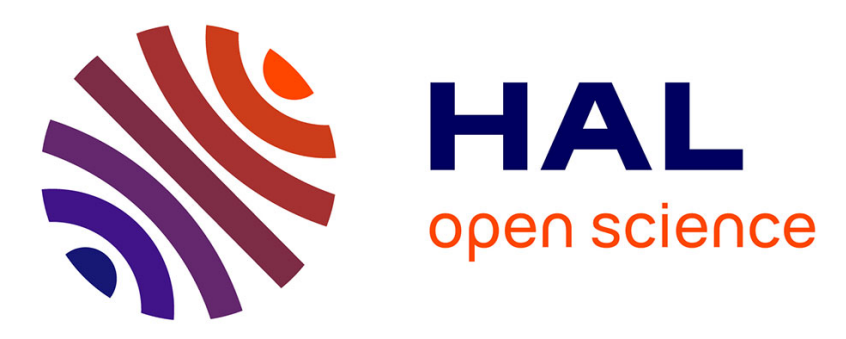

\title{
Magnetic-field effect in MOS transistor with injecting source
}

\author{
V.S. Lysenko, R.N. Litovskii, Ch. S. Roumenin, N.D. Smirnov
}

\section{To cite this version:}

V.S. Lysenko, R.N. Litovskii, Ch. S. Roumenin, N.D. Smirnov. Magnetic-field effect in MOS transistor with injecting source. Revue de Physique Appliquée, 1983, 18 (2), pp.87-92. 10.1051/rphysap:0198300180208700 . jpa-00245076

\section{HAL Id: jpa-00245076 https://hal.science/jpa-00245076}

Submitted on 1 Jan 1983

HAL is a multi-disciplinary open access archive for the deposit and dissemination of scientific research documents, whether they are published or not. The documents may come from teaching and research institutions in France or abroad, or from public or private research centers.
L'archive ouverte pluridisciplinaire HAL, est destinée au dépôt et à la diffusion de documents scientifiques de niveau recherche, publiés ou non, émanant des établissements d'enseignement et de recherche français ou étrangers, des laboratoires publics ou privés. 


\title{
Magnetic-field effect in MOS transistor with injecting source
}

\author{
V. S. Lysenko, R. N. Litovskii \\ Institute of Semiconductors, Academy of Sciences of the Ukrainian SSR, Kiev-252028, USSR
}

Ch. S. Roumenin and N. D. Smirnov

Institute of Solid State Physics, Bulgarian Academy of Sciences, Sofia-1184, Bulgaria

(Reçu le ler juillet 1982, révisé le 28 octobre, accepté le 3 novembre 1982)

\begin{abstract}
Résumé. - On a étudié expérimentalement les caractéristiques de sortie (courant-tension) d'un transistor MOS, fabriqué par une technologie habituelle à canal $\mathrm{p}$. La jonction $\mathrm{p}^{+}$-n source-substrat est en régime injectant. On a étudié l'influence d'un champ magnétique qui dévie les porteurs de charge vers l'interface $\mathrm{Si}_{-} \mathrm{SiO}_{2}$, ou vers la face opposée de l'échantillon. On a observé qu'il est possible de varier l'intensité du courant source-drain en fonction du champ magnétique. En présence d'une injection, la modulation du courant source-drain par la tension de grille est beaucoup plus efficace que dans le cas où l'injection manque. Cette sensibilité magnétique est liée avec l'effet de magnétorésistance classique qui croît avec la diminution de la température.
\end{abstract}

\begin{abstract}
The $I-V$ characteristics of a $\mathrm{p}^{+}-\mathrm{n}-\mathrm{p}^{+}$planar MOS transistor made by the standard technology under the regime of injecting $\mathrm{p}^{+}-\mathrm{n}$ source-substrate junction without and in the presence of an outer magnetic-field $B$, which deviates the carriers toward the $\mathrm{Si}-\mathrm{SiO}_{2}$ interface or in the opposite direction, were experimentally investigated. A control by $B$ of the drain-source current $I_{\mathrm{DS}}$ was observed. The current $I_{\mathrm{DS}}$ and the control of its steepness through the gate bias considerably exceeded the values obtained in the absence of injection. This effect was explained with the increase of the part of the injected current-carriers from the channel at a growing gate bias and with the decrease of the effective distance source-drain. The magnetosensitivity can be connected with the hole current which is controlled by the magnetic-field and sharply increases with the drop of temperature.
\end{abstract}

1. Introduction. - The wide application in practice and various functional capabilities of MOS transistor (MOST) are based on the fact that their channel current can be controlled and directed by changing one of the following electric parameters : the drain bias, the gate bias or the substrate bias. In the last case on the p-n source-substrate junction a reverse bias was applied, by which the conductivity of the inverse channel between the source and the drain can be modulated in certain limits. In MOS transistor electronics the reverse substrate bias method is used for changing and regulating the threshold bias of n-channel MOST with high density of the surface states in the oxide and along the $\mathrm{Si}-\mathrm{SiO}_{2}$ interface, as well as for a precise correction of the working point in the $I-V$ characteristics of MOST. Similarly, by applying the reverse bias to the substrate it is possible to compensate the temperature changes in the threshold bias of MOS integrated circuits, while with MOS memories the capacitance of $p-n$ junctions in the substrate is reduced and the speed of operation of the circuits improves [1-3].

Of certain interest is also the possibility for forward biasing of the p-n source-substrate junction. An analysis of the electric and galvanomagnetic properties of a technologically standard MOST with injecting source was performed in $[4,5]$, these initial investigations being of phenomenological nature. Similarly, there has been offered a preliminary qualitative model of the total current in the structure, in which two diffusion components $I_{\mathrm{DS}}^{\text {dif }}$ and $I_{\mathrm{SS}}^{\text {dif }}$ are supposed to appear in addition to the channel current $I_{\text {DS }}^{\text {f.e. }}$. The first one passes through the neutral part of the silicon substrate below the space charge region (SCR) of the channel and closes the electric circuit source-drain even at a zero gate bias. $I_{\mathrm{SS}}^{\text {dif }}$ consists of minority carriers injected by the source into SCR of the inverse channel. The minority carriers are caught by the channel and change the source-drain current under the influence of the surface potential barrier. It should also be noted 
that the magnetosensitivity of MOST, working under the regime of injecting source at $T=77 \mathrm{~K}$, exceeds $10^{5} \mathrm{~V} / \mathrm{A} . \mathrm{T}$.

The aim of the present paper is to continue and clarify the experimental and theoretical investigations made along this line.

2. Experimental. - In our experiments we used technologically standard p-channel MOST employed in control structures for integrated circuits. The bulk specific resistivity of the initial $\mathrm{n}$-silicon substrate oriented in the (111) direction with thickness $d \sim 180 \mu \mathrm{m}$, was $\rho \sim 7.5 \mathrm{ohm}$.cm. The thickness of $\mathrm{SiO}_{2}$ below the gate electrode was $\sim 1800 \AA$. The distance between the source and the drain was $l=100 \mu \mathrm{m}$. Al was used as material for the gate and for the metal electrodes with $\mathrm{p}^{+}$-diffusion regions. The structures investigated were mounted on dual-in-line package with 12 (metal) or 22 (metalloceramic) pins.

The electric circuit of MOST connection for studying its electric and galvanomagnetic characteristics is presented in figure 1. A characteristic feature is that the

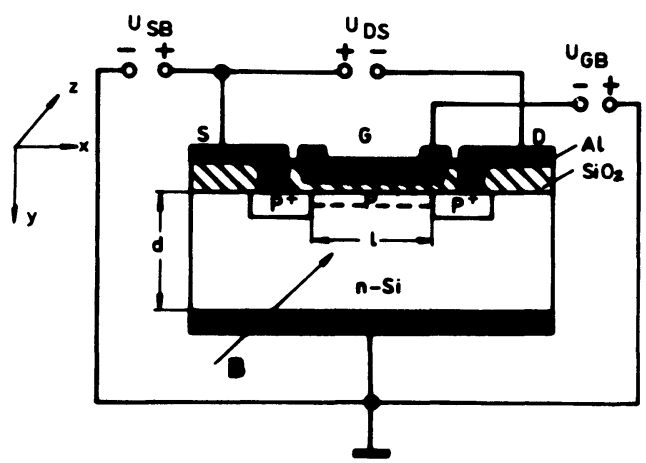

Fig. 1. - Electric circuit of MOST connection used in the experiments.

$\mathrm{p}^{+}-\mathrm{n}$ source-substrate junction can be biased in a forward direction by means of an additional source of constant bias $U_{\text {SB }}$ and the outer magnetic-field B is applied in the $\mathrm{Si}_{-} \mathrm{SiO}_{2}$ plane, perpendicular to the source-drain current $I_{\mathrm{DS}}$. The current signal $I_{\mathrm{DS}}$ was recorded automatically by a $X-Y$ recorder. The experiments were carried out at room $(T=300 \mathrm{~K})$ and at nitrogen $(T=77 \mathrm{~K})$ temperatures, in dark, in order to eliminate photoeffect in MOST, the experimental error not exceeding $1 \%$. For this purpose the samples were mounted on a special stainless steel holder, placed in a cryostat suitable for magnetic measurements. A Weiss-type electromagnet with water cooling was used to produce an external magnetic-field with an intensity up to $B=1.5 \mathrm{~T}$.

The graphic results of the dependence of the channel current $I_{\mathrm{DS}}$ in MOST as a function of the bias $U_{\mathrm{DS}}$ in the linear, transition and saturated regions for different $U_{\mathrm{GB}}$ when $U_{\mathrm{SB}}=0$ and $T=77 \mathrm{~K}$, are shown in figure 2. It was established by the analysis of the

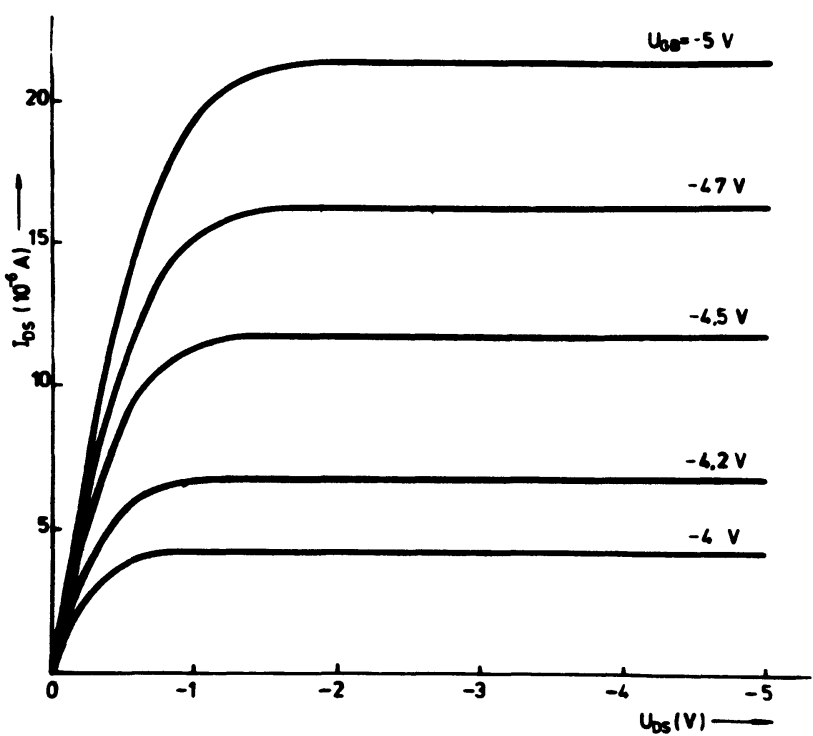

Fig. 2. - Initial $I-V$ characteristics $I_{\mathrm{DS}}\left(U_{\mathrm{DS}}\right)$ of MOST as a parameter of $U_{\mathrm{GB}}$ for $U_{\mathrm{SB}}=0$ at $T=77 \mathrm{~K}$.

transition characteristics $I_{\mathrm{DS}}\left(U_{\mathrm{GB}}\right)$ that the threshold bias $U_{\mathrm{T}}$ at $T=300 \mathrm{~K}$ and $T=77 \mathrm{~K}$ is $-2.3 \mathrm{~V}$ and $-2.8 \mathrm{~V}$ respectively. Figure 2 shows that the initial characteristics $I_{\mathrm{DS}}\left(U_{\mathrm{DS}}\right)$ in the structures investigated are analogous to those obtained in MOST, functioning under the usual regime, i.e. at $U_{\mathrm{SB}}=0$. Similarly, the outer magnetic-field $\mathbf{B}$ does not produce any effect on the channel current $I_{\mathrm{Ds}}$ at $T=300 \mathrm{~K}$ and $T=77 \mathrm{~K}$ up to values $B=1.5 \mathrm{~T}$ within the experimental error.

The effect of the forward bias $U_{\mathrm{SB}}$ on the initial characteristics of the transistor $I_{\mathrm{DS}}\left(U_{\mathrm{DS}}\right)$ is shown in figure $3 a, b$. A considerable increase of the $I_{\mathrm{DS}}$ current as a function of $U_{\mathrm{SB}}$ was observed, at that its sensitivity from the gate bias $U_{\mathrm{GB}}$ in the unsaturated region substantially exceeding the values obtained at $U_{\mathrm{SB}}=0$. The dependence $I_{\mathrm{DS}}\left(U_{\mathrm{DS}}\right)$ for $U_{\mathrm{SB}}=0$ and $U_{\mathrm{GB}}=$ $-5 \mathrm{~V}$ is presented in figure 3 for the sake of comparison. Another important feature is that for $U_{\mathrm{DS}}>U_{\mathrm{P}}$, where $U_{\mathrm{P}}$ is the channel pinch-off voltage, the current $I_{\text {DS }}$ is not a constant value, but keeps rising with the increase of $U_{\text {DS. }}$.

The $B-I$ characteristics of MOST with injecting source are presented in figure $4 a, b$. We assumed for positive direction of the magnetic field $(+B)$ the direction in which the injected current carriers are deflected towards the $\mathrm{Si}-\mathrm{SiO}_{2}$ interface. It should be noted that besides the appearance of magnetosensitivity at $U_{\mathbf{G B}}=0$, a magnetic-field effect is also observed, which consists in the modulation of the magnetic control of $I_{\mathrm{DS}}(\mathbf{B})$ by $U_{\mathrm{GB}}$. The curves obtained are symmetrical with respect to the change of the induction sign of $\mathbf{B}$, while at $B>B_{0}$ there is a tendency towards saturation. The characteristic magnetic-field $B_{0}$ in the experiments at $T=77 \mathrm{~K}$ is about $1 \mathrm{~T}$. It follows also from the results that the increase of $U_{\mathrm{GB}}$, at $U_{\mathrm{SB}}=$ const., does not influence the nature of the dependence $I_{\mathrm{DS}}(\mathbf{B})$, as well as the values $B_{0}$ and $B_{\max }$, 


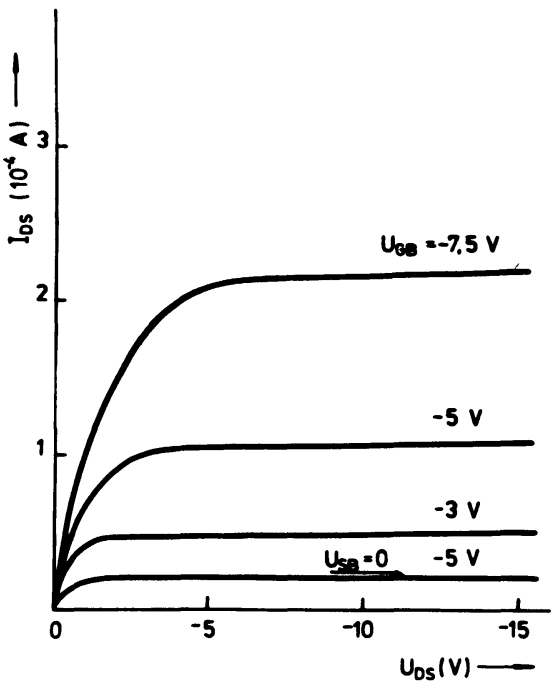

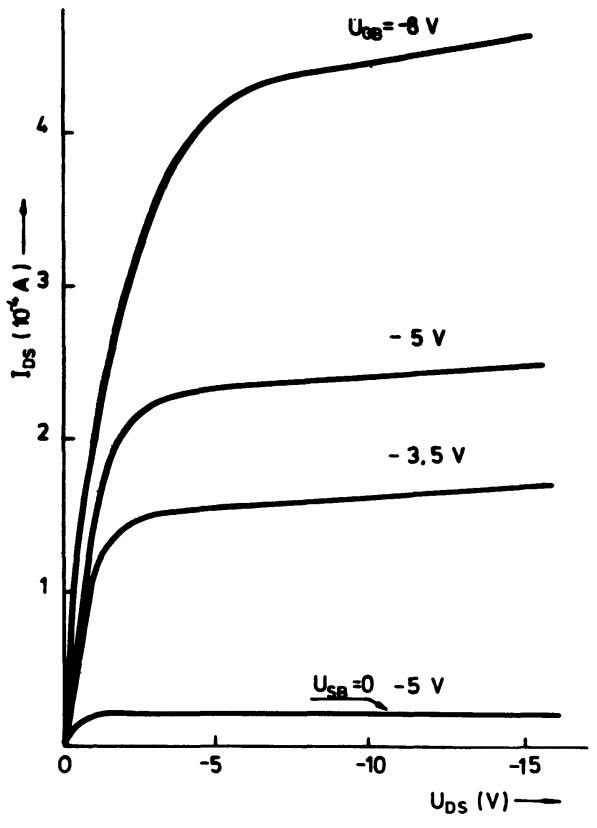

B

Fig. 3. - Influence of the forward bias $U_{\mathrm{SB}}$ on the curves $I_{\mathrm{DS}}\left(U_{\mathrm{DS}}\right)$ as a parameter of $U_{\mathrm{GB}}$ at $\left.T=77 \mathrm{~K} ; a\right) U_{\mathrm{SB}}=1.14 \mathrm{~V}$, b) $U_{\mathrm{SB}}=1.35 \mathrm{~V}$.

where $B_{\max }$ is the induction at which the current $I_{\mathrm{DS}}$ attains its maximum (Fig. 4). For relatively low values of $U_{\mathrm{SB}}: 0.8 \mathrm{~V}<U_{\mathrm{SB}} \lesssim 1 \mathrm{~V}$ at $T=77 \mathrm{~K}$, the magneto-sensitivity of MOST is small. The value $U_{\mathrm{SB}}=0.8 \mathrm{~V}$ represents the threshold voltage for opening the $p^{+}-n$ diode source-substrate. The analogous voltage at $T=300 \mathrm{~K}$ is $U_{\mathrm{SB}}=0.4 \mathrm{~V}$. It should be noted that for $U_{\mathrm{SB}}<0.4 \mathrm{~V}(T=300 \mathrm{~K})$ and $U_{\mathrm{SB}}<0.8 \mathrm{~V}$ $(T=77 \mathrm{~K})$, despite the fact that the source junction is biased in forward direction, a magnetic control of the current is not observed.

With the increase of $U_{\mathrm{SB}}>1 \mathrm{~V}(T=77 \mathrm{~K})$ a shifting of the maximum in the $I_{\mathrm{DS}}(\mathrm{B})$ curves is observed in the region of the positive values of $B$ the higher the value of $U_{\mathrm{SB}}$, the greater the value of $B_{\max }$. This feature is illustrated in figure 5 .

In order to clarify the influence of the substrate current $I_{\mathrm{SB}}\left(U_{\mathrm{SB}}\right)$ on the electrical and galvanomagnetic properties of the MOST investigated we measured the $I-V$ characteristics in the forward direction of the $\mathrm{p}^{+}-\mathrm{n}$ junction, namely the source-substrate current $I_{\mathrm{SB}}\left(U_{\mathrm{SB}}\right)$.

The results obtained show that at $T=77 \mathrm{~K}$ in the interval $0.8 \mathrm{~V} \leqslant U_{\mathrm{SB}} \lesssim 1 \mathrm{~V}$, the current $I_{\mathrm{SB}}$ increases exponentially while for $U_{\mathrm{SB}}>1 \mathrm{~V}$ the $I-V$ dependence is practically linear. The reason for this behaviour of the $I-V$ characteristics is that for $U_{\mathrm{SB}}>1 \mathrm{~V}$ the applied voltage $U_{\mathrm{SB}}$ falls entirely on the series resistance of the substrate. On the other hand, exactly at $U_{\mathrm{SB}} \gtrsim 1 \mathrm{~V}$, the shift of the maximum of the $I_{\mathrm{DS}}(\mathrm{B})$ curves toward the positive values of $B$ is observed (see Fig. 5).

The observed characteristics of MOST under the injecting source regime of work at $T=77 \mathrm{~K}$ remain the same at $T=300 \mathrm{~K}$ as well, but the effect of the magnetic-field B in the current $I_{\mathrm{Ds}}$ is substantially smaller. Thus, for instance, for $U_{\mathrm{GB}}=-3.5 \mathrm{~V}$, $U_{\mathrm{DS}}=-4 \mathrm{~V}$ and $U_{\mathrm{SB}}=0.75 \mathrm{~V}$ at $B=1.5 \mathrm{~V}$, the current $I_{\mathrm{DS}}$ decreases by $7 \%$.

3. Discussion. - 3.1. - Let us examine the distribution of the potential in the channel of $p^{+}-n-p^{+}$ MOST, when the following relation is valid :

$$
U_{\mathrm{SB}} \lesssim U_{\mathrm{SB}}^{(0)}=(2 k T / q) \ln N_{\mathrm{D}} / n_{i}
$$

where the bias $U_{\mathrm{SB}}^{(0)}$ corresponds to the condition for a strong hole injection near the source, $p \sim N_{\mathrm{D}}$. (In (1) and further we used standard designations.) According to [1] the dependence of the channel-source voltage $U(x)$ on the coordinate $x$ when the inverse channel is formed can be expressed in the following way :

$$
\begin{aligned}
x-l=\left(W \mu_{\mathrm{p}} C_{\mathrm{OX}} / I_{\mathrm{DS}}\right)\left[\left(U_{\mathrm{DB}}^{2}-U^{2}(x)\right) / 2-\right. \\
\left.-\left(U_{\mathrm{GB}}-U_{\mathrm{T}}\right)\left(U_{\mathrm{DB}}-U(x)\right)\right],
\end{aligned}
$$

where $W$ is the width of the inverse channel; $\mu_{\mathrm{p}}$ is the channel mobility of the holes; $C_{\mathrm{Ox}}$ is the capacitance of the oxide - under the gate, and $U_{\mathrm{DB}}$ is the drainsubstrate voltage.

The static $I-V$ characteristics of the p-channel MOST at $U_{\mathrm{SB}}>0$ can be obtained replacing in (2) at $x=0, U(x)=U_{\mathrm{SB}}$, i.e.

$$
\begin{aligned}
I_{\mathrm{DS}}=\left(W \mu_{\mathrm{p}} C_{\mathrm{OX}} / l\right) & {\left[\left(U_{\mathrm{SB}}^{2}-U_{\mathrm{DB}}^{2}\right) / 2+\right.} \\
+ & \left.\left(U_{\mathrm{GB}}-U_{\mathrm{T}}\right)\left(U_{\mathrm{DB}}-U_{\mathrm{SB}}\right)\right]
\end{aligned}
$$




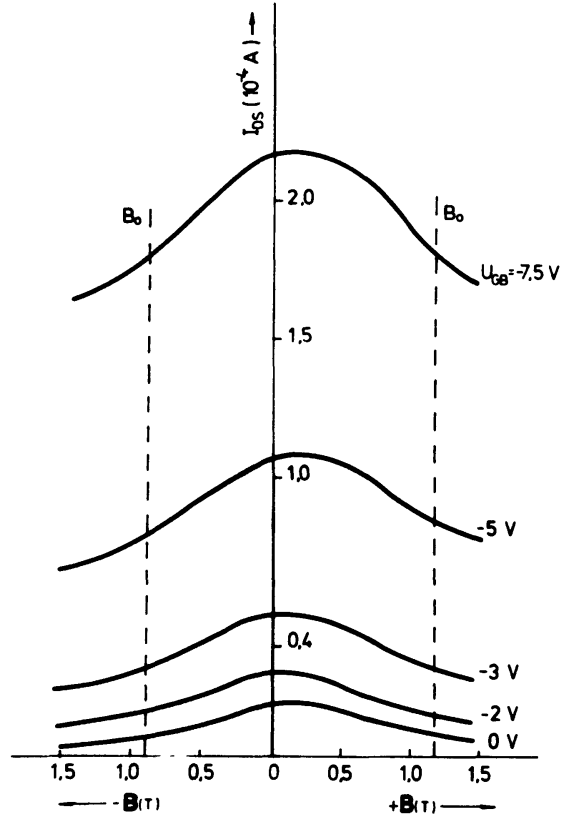

a)

Fig. 4. $-I-B$ dependence $I_{\mathrm{DS}}(\mathrm{B})$ of MOST with injecting source as a parameter of $U_{\mathrm{GB}}$ at $T=77 \mathrm{~K}$ and $U_{\mathrm{DS}}=$ $\left.-10 \mathrm{~V}: a) U_{\mathrm{SB}}=1.14 \mathrm{~V}, b\right) U_{\mathrm{SB}}=1.35 \mathrm{~V}$.

For the saturated regime of the $I_{\mathrm{DS}}$ current $U_{\mathrm{DB}}$ should be substituted by $\left(U_{\mathrm{GB}}-U_{\mathrm{T}}\right)$. From (2) we determine the coordinate $x_{0}$, in which $U\left(x_{0}\right)=0$ :

$x_{0}=l \frac{U_{\mathrm{SB}}^{2} / 2-\left(U_{\mathrm{GB}}-U_{\mathrm{T}}\right) U_{\mathrm{SB}}}{\left(U_{\mathrm{SB}}^{2}-U_{\mathrm{DB}}^{2}\right) / 2+\left(U_{\mathrm{GB}}-U_{\mathrm{T}}\right)\left(U_{\mathrm{DB}}-U_{\mathrm{SB}}\right)}$.

Upon the connection method of MOST employed in our experiments (Fig. 1), as compared to [1], it is

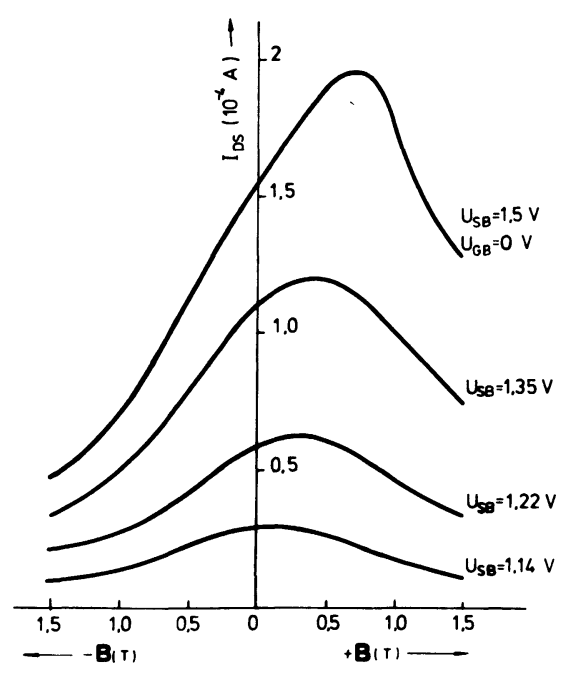

Fig. 5. - Influence of the bias $U_{\mathrm{SB}}$ on the maximum of the $I_{\mathrm{DS}}(\mathrm{B})$ curves at $T=77 \mathrm{~K} ; U_{\mathrm{Ds}}=-10 \mathrm{~V} ; U_{\mathrm{GB}}=$ $-2 \mathrm{~V}$.

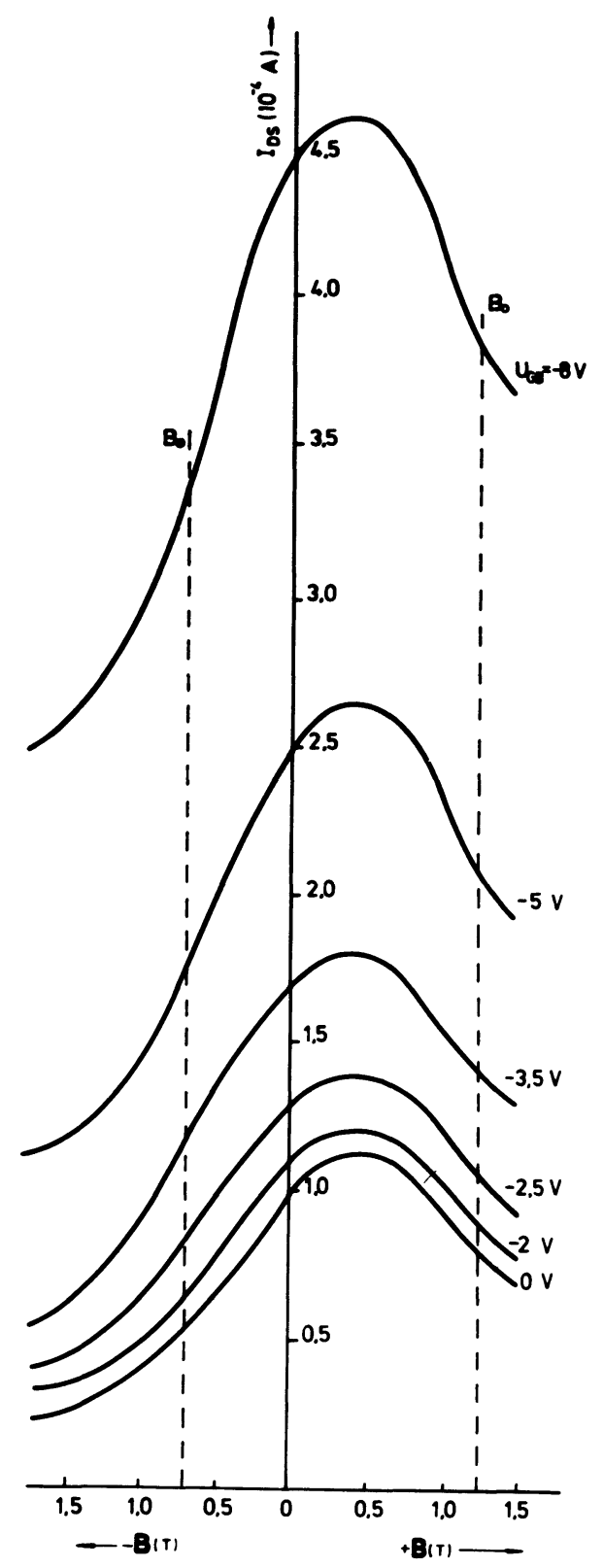

b)

necessary in (2)-(4) to substitute $U_{\mathrm{DB}}$ with $\left(U_{\mathrm{DS}}+U_{\mathrm{SB}}\right)$. We suppose that $l \gg L_{\mathrm{D}}=\left(\varepsilon_{0} \varepsilon_{\mathrm{s}} k T / q^{2} N_{\mathrm{D}}\right)^{1 / 2}$, where $L_{\mathrm{D}}$ is the screening length in the substrate, so that the Early effect is neglected. Since in the p-channel MOST $U_{\mathrm{GB}}<0, U_{\mathrm{DB}}<0$, while $U_{\mathrm{SB}}>0$, then the increase of $\left|U_{\mathrm{GB}}-U_{\mathrm{T}}\right|$ at certain values of. $U_{\mathrm{DB}}$ and $U_{\mathrm{SB}}$ leads to shifting of point $x_{0}$ from the source toward the drain. E.g., for $U_{\mathrm{SB}}=0.5 \mathrm{~V}, U_{\mathrm{DB}}=-3 \mathrm{~V}$ and $\left(U_{\mathrm{GB}}-U_{\mathrm{T}}\right)=-4 \mathrm{~V}$, the relation $x_{0} / l$ is $\sim 0.2$.

The increase of $x_{0} / l$ leads to redistribution of the current due to the injected holes between $\mathrm{p}^{+}$-source and $\mathrm{p}$-channel, which is equivalent to reducing the effective length of the source-drain $l^{*}$. This effect determines the current of the injected holes as a function of the voltage $U_{\mathrm{GB}}$, as shown in figure 3 . 
3.2. - For the analysis of the transport process in MOST with injecting source one can examine the simplified model illustrated in figure 6 . In this model a cylindrical symmetry is assumed, i.e. the length of the electrodes in the direction of the $z$ axis, as well as the substrate thickness $d$, substantially exceed the diffusion length of the holes $L_{\mathrm{p}}$. Since the case when $l \sim L_{\mathrm{p}}$ is of great interest, then the assumption is valid for a very low rate of the surface recombination $S$ of the $\mathrm{Si}_{-} \mathrm{SiO}_{2}$ interface. The " collector " which collects the injected holes is situated in the region between $l^{*}$ and the drain (point D), i.e. in the region $\left(l^{*}+b\right)$, where $b$ is the distance between $l^{*}$ and the drain $\mathrm{D}$.

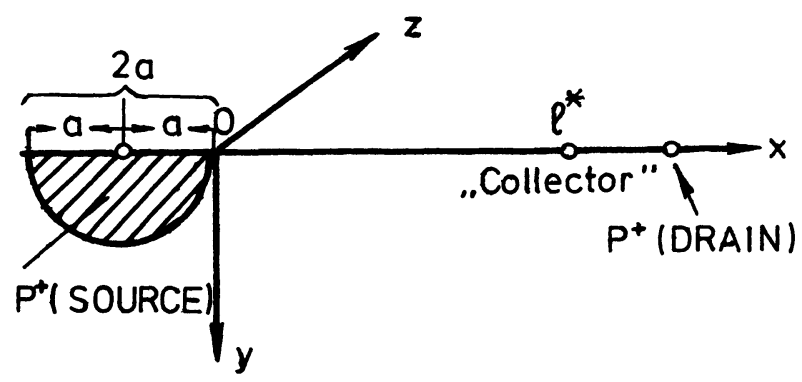

Fig. 6. - Simplified graphic model for current analysis in MOST with injecting source.

Assuming the existence of cylindrical symmetry, the hole concentration $p$ as a function of the cylinder's radius $r \equiv x$ is given by the expression :

$$
p(r)=C \cdot K_{1}(r) \cdot \sin \theta
$$

where $C$ is the integration constant :

$$
K_{1}(r) \equiv K_{1}(x)=\int_{0}^{\infty} \exp (-x \cdot \operatorname{ch} t) \cdot \operatorname{ch} t \mathrm{~d} t
$$

is the Bessel function of type I, [6].

Neglecting the drift current component of the holes in the substrate and solving the continuity equation analogously to the one-dimensional case [7], we get the following expression for the $y$-component of the current density at strong injection :

$$
\left.j_{\mathrm{p}, y}\right|_{y=0}=-\left.\frac{D_{\mathrm{p}}}{r} \cdot \frac{\partial p}{\partial \theta}\right|_{\theta=0}=-C \frac{D_{\mathrm{p}}}{L} \cdot \frac{K_{1}(x)}{x}
$$

where $D_{\mathrm{p}, \mathrm{n}}$ is the diffusion coefficient of the holes and the electrons $L=\left(2 D_{\mathrm{p}} \cdot D_{\mathrm{n}} \tau / D_{\mathrm{p}}+D_{\mathrm{n}}\right)^{1 / 2} ; \tau$ is the lifetime of the electron-hole pairs.

At a low level of injection $\tau$ should be substituted by $\tau_{\mathbf{p}}$, where $\tau_{\mathrm{p}}$ is the lifetime of the holes, and accordingly $L$ is substituted by $L_{\mathrm{p}}=\left(D_{\mathrm{p}} \cdot \tau_{\mathrm{p}}\right)^{1 / 2}$, where $L_{\mathrm{p}}$ is the diffusion length.

In order to find the integration constant $C$ in equation (5) one should take into account that the radial component of the current density normal to the cylinder's surface may be expressed as :

$$
j_{\mathrm{p}, \mathrm{r}}=-D_{\mathrm{p}} \frac{\partial p}{\partial r}=-\frac{D_{\mathrm{p}}}{L} \cdot \frac{\partial p}{\partial x} .
$$

The boundary condition is determined by the fact that the total current through the source surface $I_{S}$ is

$$
\begin{aligned}
& \int j_{\mathrm{p}, r} \mathrm{~d} S \text { (on Fig. } 6 r=a \text { ). Therefore, } \\
& \qquad C=\frac{I_{\mathrm{S}}}{\left(2 D_{\mathrm{p}} / L\right)\left[-\mathrm{d} K_{1}(x) / \mathrm{d} x\right]_{x=a / L}} .
\end{aligned}
$$

In order to find the drain current (5) should be integrated on the «drain" area :

$$
I_{\mathrm{DS}}^{\mathrm{dif}}=I_{\mathrm{S}} \cdot \frac{\int_{l^{*} / L}^{\left(l^{*}+b\right) / L}\left(K_{1}(x) / x\right) \mathrm{d} x}{2\left[-\mathrm{d} K_{1}(x) / \mathrm{d} x\right]_{x=a / L}}
$$

$l^{*} \sim l-x_{0}$ can be assumed as a qualitative explanation of the experimental dependence observed. This assumption is not very exact, since for the determination of the coordinate dependence of the injection, current it is necessary to solve a self-coordinated twodimensional problem which takes into account the quasi-Fermi level dependence of the holes on the injection current density. In addition, in case of injection, there is an enrichment of the substrate by the holes near the source, which changes the potential distribution $U(x)$. The coordinate $x_{0}$ is no more described by (4), and it increases with the increase of $\left(U_{\mathrm{GB}}-U_{\mathrm{T}}\right)$.

When $U_{\mathbf{S B}}>U_{\mathbf{S B}}^{(0)}$ the concentration of the injected holes in the source region exceeds that of $N_{\mathrm{D}}$ and the potential barrier channel-substrate disappears. The growth of $\left(U_{\mathrm{GB}}-U_{\mathrm{T}}\right)$ leads to an increase of the number of holes landing in the inverse channel. As a result, the effective value of $l^{*}$ decreases, which according to (7) leads to the increase of the current $I_{\mathrm{DS}}^{\mathrm{dif}}$. As follows from figures 2 and 3 the dependence $I_{\mathrm{DS}} \sim\left(U_{\mathrm{GB}}-U_{\mathrm{T}}\right)^{2}$ at $U_{\mathrm{SB}} \sim 0$ is substituted by $I_{\mathrm{DS}} \sim\left(U_{\mathrm{GB}}-U_{\mathrm{T}}\right)^{\alpha}$ for $U_{\mathrm{SB}}>U_{\mathrm{SB}}^{(0)}$, where $1 \lesssim \alpha<2$. This is connected with the circumstance that the effective concentration of the holes in the channel is no more proportional to $\left(U_{\mathrm{GB}}-U_{\mathrm{T}}\right)$, as in the quasinonequilibrium case $U_{\mathrm{SB}}-U_{\mathrm{SB}}^{(0)}$, and the channel bias grows with the growth of $\left(U_{\mathrm{SB}}-U_{\mathrm{T}}\right)$ (for $U_{\mathrm{SB}}<U_{\mathrm{SB}}^{(0)}$ it is equal to $\left.\left(U_{\mathrm{DB}}-U_{\mathrm{T}}\right)\right)$. Since the concentration of the holes in each point depends on $x / L$, then the growth of the slope $d I_{D S} / d U_{D S}$ of the initial curves at $U_{\mathrm{DS}}>U_{\mathrm{P}}$ is a natural consequence (Fig. 3). As the current's diffusion component according to (7) is proportional to $\exp \left(-l^{*} / L\right)$, then a slight alteration of $\Delta l^{*}$ as a result of the Early effect, $\Delta l^{*}=2 L_{\mathrm{D}} \times$ $\left[\left(U_{\mathrm{SB}}-U_{\mathrm{DB}}\right) /(k T / q)\right]^{1 / 2}$, leads to a visible increase of the drain current. 
3.3. - The considerable magnetosensitivity arising at $T=77 \mathrm{~K}$ is connected with the influence of the magnetic field $B$ on the bulk mobility of the injected holes $\mu_{\mathrm{p}}^{(v)}$. At $U_{\mathrm{SB}}<U_{\mathrm{SB}}^{(0)}$ there is no voltage drop in the silicon substrate volume, and the dependence is symmetric with the commutation of $\mathbf{B}$, the characteristic magnetic induction $B_{0}$ being $1 \mathrm{~T}$. From the nature of the effect of the outer magnetic field on $I_{\mathrm{DS}}$ for $B<B_{0}$ and $B>B_{0}$ one may conclude that the reason for magnetosensitivity in the structure is the classical magnetoresistant effect. In this connection the characteristic induction $B_{0}$ corresponds to the condition

$$
\mu^{2} B^{2} \approx 1 .
$$

On the other hand, it was experimentally established that $\mu_{\mathrm{p}}^{(v)}$ is $10^{4} \mathrm{~cm}^{2} \cdot \mathrm{v}^{-1} \cdot \mathrm{s}^{-1}$ [8] at $T=77 \mathrm{~K}$ and according to (8) it follows that $B_{0} \sim 1 \mathrm{~T}$, which agrees with the experimental values of $B_{0}$. The saturation of $I_{\mathrm{DS}}(\mathrm{B}) B>B_{0}$ is also a result of the magnetoresistant effect and it is connected with the limited size of the samples, $d>L_{\mathrm{p}}$ [9].

With the growth of $U_{\mathrm{SB}}-U_{\mathrm{SB}}^{(0)}$ there appears an $y$-component of the electric field in the substrate. This leads to the shifting of the maximum of the curves $I_{\mathrm{DS}}(\mathrm{B})$ (Fig. 5), in the region of the positive values of the magnetic induction, i.e. upon deflection towards the $\mathrm{Si}-\mathrm{SiO}_{2}$ interface. The greater the difference $U_{\mathrm{SB}}-U_{\mathrm{SB}}^{(0)}$, the bigger is the value of $B_{\max }$. This peculiarity also proceeds from the asymmetry of the examined problem.

It should be mentioned that in the framework of the proposed model the magnetic-field effect is not connected with the Suhl effect, because the role of the surface recombination is insignificant. The reason for that is the high quality of the $\mathrm{Si}-\mathrm{SiO}_{2}$ interface in the samples studied, as well as the presence of an inverse p-channel, $d, l \sim L_{\mathrm{p}}$. This conclusion is confirmed by the absence of magnetosensitivity in the structures at $U_{\mathrm{SB}}=0$ in magnetic fields $B \sim 1.5 \mathrm{~T}$ and by the symmetry of the curves $I_{\mathrm{DS}}(\mathrm{B})$.

4. Conclusion. - A qualitative comparison between the experimental results and the proposed model was made. It should be noted, however, that it was impossible to perform an exact quantitative analysis of theory and experiment. The main reason for that lies in the fact that the investigations were not carried out on structures specially designed for our experiment, but on widely used in practice standard p-channel MOST. To perform a detailed analysis it is necessary to have first of all a structure with linear dimensions, bigger or smaller than the diffusion length of the injected holes $L_{\mathbf{p}}$. In our case, however, the structure had dimensions approximately equal to $L_{\mathrm{p}}$. There was a possibility to employ a computer modelling procedure, but our aim was to give a principal interpretation of the obtained results, using a conventional MOST structure.

From the experimentally obtained results and from the above discussion it may be concluded that the optimization of the magnetic-field effect in MOST with injecting source can be achieved by application of the $n^{+}-p-n^{+}$planar structures because of the higher mobility of the injected electrons, $\mu_{\mathrm{n}}^{(v)}>\mu_{\mathrm{p}}^{(v)}$.

Acknowledgments. - The authors wish to express their gratitude to Prof. J. Kassabov from the Institute of Solid State Physics, corresponding member of the Bulgarian Academy of Sciences, and to Prof. Dr. Z. Gribnikov from the Institute of Semiconductors at the Ukrainian Academy of Sciences, USSR, for their constant interest in the process of work and for the fruitful discussions.

\section{References}

[1] Penney, W. M., LaU, L., MOS Integrated Circuits, Microelectronics Series (Van Nostrand Rein. Comp., New York) 1972, chap. 2-\$ 3.4, § 4.6; chap. 3-\$ 4.1.

[2] Cobbold, R. S. C., Theory and Application of FieldEffect Transistors (Willey-Interscience a Division of John and Sons, New York) 1970, chap. 7-\$1; $\S 2$.

[3] Wallmark, J. T., Johnson, H., Field-Effect Transistors (Prentice-Hall, Englewood Clifs, New Jersey), chap. $5, \S 2(6)$.
[4] Smirnov, N., Roumenin, Ch., Velchev, N., Bulg. J. Phys. 8(4) (1981) 390.

[5] Smirnov, N., Roumenin, Ch., Stoev, I., Velchev, N., Bulg. J. Phys. 8(5) (1981) 499.

[6] Korn, G. A., Korn, T. M., Mathematical Handbook for Scientists and Engineers (McGraw-Hill, New York) 1961.

[7] Lampert, M. A., Mark, P., Current Injection in Solids (Academic Press, London) 1970.

[8] Morin, F. J., Maita, J. P., Phys. Rev. 96(1) (1954) 28.

[9] Kireev, P. S., Semiconductor Physics, Moskva, 1975. 